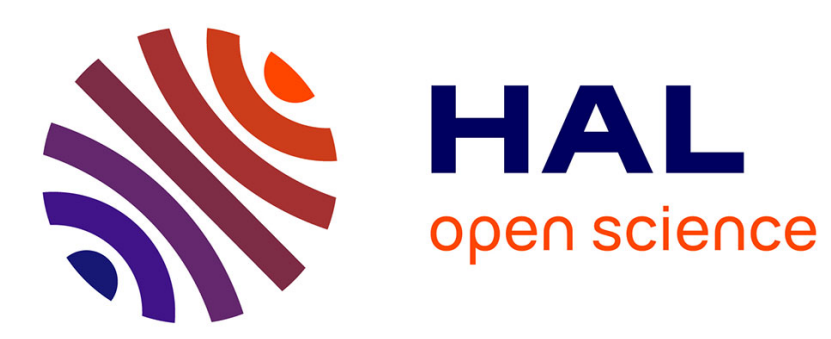

\title{
User-Centered Design of an Online Mobile Game Suite to Affect Well-Being of Older Adults
}

\author{
Isabelle Kniestedt, Stephan Lukosch, Frances Brazier
}

\section{To cite this version:}

Isabelle Kniestedt, Stephan Lukosch, Frances Brazier. User-Centered Design of an Online Mobile Game Suite to Affect Well-Being of Older Adults. 17th International Conference on Entertainment Computing (ICEC), Sep 2018, Poznan, Poland. pp.355-361, 10.1007/978-3-319-99426-0_44 . hal02128629

\section{HAL Id: hal-02128629 \\ https://hal.inria.fr/hal-02128629}

Submitted on 14 May 2019

HAL is a multi-disciplinary open access archive for the deposit and dissemination of scientific research documents, whether they are published or not. The documents may come from teaching and research institutions in France or abroad, or from public or private research centers.
L'archive ouverte pluridisciplinaire HAL, est destinée au dépôt et à la diffusion de documents scientifiques de niveau recherche, publiés ou non, émanant des établissements d'enseignement et de recherche français ou étrangers, des laboratoires publics ou privés. 


\title{
User-Centered Design of an Online Mobile Game Suite to Affect Well-Being of Older Adults ${ }^{\star}$
}

\author{
Isabelle Kniestedt, Stephan Lukosch and Frances Brazier \\ Delft University of Technology, Delft, The Netherlands
}

\begin{abstract}
This paper describes the ongoing design process of Pocket Odyssey, an online multi-player game suite designed for mobile phones that supports older adults in maintaining their physical, social, and mental well-being. It has been designed to provide engaging gameplay that supports positive emotion, fosters online social connections between players, enables play with others in a player's physical surroundings, and integrates tasks that exercise physical and cognitive skills. This paper discusses the user-centered design approach that takes entertainment preferences, views on technology, and aspects of life that older adults consider meaningful as a basis. Based on the results of an exploratory survey and a series of workshops with the user group, this paper presents the initial game concept and the rationale behind its design. Finally, it describes early prototyping efforts and future activities.
\end{abstract}

Keywords: User-centered design · Game · Well-being · Older adults

\section{Introduction}

Understanding how to enable, acquire and maintain a feeling of well-being is a challenge. As life expectancy increases, the aging process comes with a variety of more specific challenges that influence a person's autonomy, social network, and the ability to act and enjoy [10]. This paper explores the potential of technological innovation, in particular of digital games, to tackle this challenge.

The effects of digital games have been studied ever since they became mainstream media [1]. With their ever increasing ubiquity, in part due to their availability on mobile devices, this field of study has only grown. Although a growing body of work points towards the short-term positive effects that games can have on players [14,12], little is known about long-term effects. Whether games can contribute to well-being over time, and how designers should approach such a task, requires more study.

This paper describes the early design of Pocket Odyssey, a mobile game suite for players over 55 years of age. This mobile game suite has been designed to (1) foster social contact both online and between players in the same physical space, (2) stimulate cognitive functioning through knowledge and reasoning-based game

* This project has received funding from the European Union's Horizon 2020 research and innovation program under grant agreement No 769643 
mechanics, and (3) encourage light physical activity by utilizing the sensors of a mobile phone. By combining these different types of play, Pocket Odyssey aims to provide positive playful experiences over an extended period of time that contribute to a player's overall well-being.

An iterative, user-centered approach has been followed, based on requirements gathered from an initial survey on leisure and entertainment preferences, including device preferences, and from four workshops that focused on factors that influence user well-being and use of technology. This paper presents the first game concept, the rationale behind the design, experience with initial prototypes, and future plans.

\section{Related Work}

Well-being is a construct that consists of multiple measurable dimensions. The main dimensions considered in the literature are: emotional well-being, that describes positive emotion or affect $[11,16,13]$ and life satisfaction [13]; psychological well-being, that addresses factors such as autonomy [15, 13], accomplishment [16], and engagement $[11,16]$; social well-being, that focuses on positive relationships $[13,15,16]$ and factors such as social acceptance, coherence, and integration [13]; and physical well-being [4]. A person's resources determine whether a stable equilibrium between these dimensions of well-being can be maintained given the challenges with which an individual is faced [8]. When challenges outweigh resources, well-being is affected negatively. In turn, when resources outweigh challenge, stagnation can occur. Therefore, maintaining a sense of equilibrium can be achieved by teaching individuals to increase their resources or the number and types of challenges with which they are faced [8].

Digital games have become both widespread entertainment media and an object of academic study. They are a dynamic, interactive medium that enables a unique form of player engagement [5]. Games often take the form of challenges to be overcome and therefore, together with other elements such as pleasing aesthetics and story, provide short-term impact on psychological and emotional well-being [14]. Another potential positive effect of games is in fostering social connections, be it through online or co-located multi-player games with friends or strangers [17].

\section{Context}

The H2020 project NESTORE, provides the context for acquisition of initial design requirements (annotated in this paper with 'RX', see Table 1), such as the ability to affect well-being in the various domains (R1), and engage players over time (R2).

To contribute to well-being over time, target users need to engage with the game over an extended period of time. To this purpose, an iterative development cycle is followed that involves testing and adapting the game in interaction with its target users at various stages of development [9]. Specific usability needs of 
older audiences have been identified on the basis of the literature (R3) [10], as well as the need for an appropriate game experience (R4) [9] based on age related interests, such as entertainment preferences [3] and factors that influence motivation [7]). Building on this existing work, direct feedback was sought from the target audience through an exploratory survey and a series of workshops in order to further inform the early stages of the design process.

\section{Interests and Technology Survey}

A survey was designed and conducted to determine the leisure and entertainment preferences of, and the types of technology used by the target audience. 30 Dutch participants participated in the survey, with ages ranging from 55 to $69(\mathrm{M}=60.8, \mathrm{SD}=3.95)$ and $67 \%$ female. Participants were asked to rate 17 leisure activities (e.g. sports, gardening, travel) and 23 entertainment genres (e.g. fantasy, action, drama), having the choice between 'Dislike', 'Neutral', 'Like', and 'I don't know' for each item. Finally, the survey contained questions relating to technology use.

The results show a variety of activities that are enjoyed by the target audience. The top five consists of travel $(83 \%)$, spending time with friends and family (80\%), reading (73\%), watching movies/tv (70\%), and listening to the radio $(70 \%)$. Regarding games in particular, $47 \%$ reported enjoying board or card games, $53 \%$ liked word or number puzzles, and 33\% liked digital games. Similarly, with respect to genres of entertainment the top five consisted of adventure, history, crime/detective, tension/thriller, and comedy.

All participants reported owning and using a smart-phone with a data connection (R5). Less frequent were the use of laptops and tablets ( $80 \%$ and $67 \%$ respectively). The dominant operating system was Android for smart-phones (60\%). A minority of participants reported playing digital games on a tablet (30\%), smart-phone $(27 \%)$, or laptop/computer $(7 \%)$.

\section{Exhibition-in-a-Box Workshops}

After the survey, a total of 17 participants took part in four workshops organized to increase understanding of factors that influence well-being and the influence of technology. Each workshop lasted approximately two hours and deployed the Exhibition-in-a-Box [6] method, which utilizes objects as associative prompts for conversation. Participants took an object from the box at random, after which they were asked to discuss what they find meaningful or technology using the object as a guide. Results from the workshops show the importance of staying active, physically and mentally, as well as maintaining social contacts as one gets older. Participants took part in many activities, for which social contact was often named as a motivator. Those who live alone mentioned relying on group activities in community centers, as opposed to those who live with a partner or who have family close by. Regarding technology, the participants indicated that systems should be easy to use (relating to R3), fit into their routine (R6), 
be designed with the user in mind (relating to R3/R4), and provide enough support as they are introduced (R7). Finally, while participants were positive about the fact that technology enables social contact with those who are further away, face-to-face contact was perceived to be very valuable (R8). Participants showed a general concern for how digital technology is changing patterns of communication.

When asked about games, participants generally expressed positive views. Opinions on digital games were mixed; particularly the level of violence and its potential effect on younger people was a cause for concern. Board games were generally seen to be a positive activity (R9), and several participants mentioned playing digital games as well, e.g. Pokemon Go ${ }^{1}$, Farm Heroes Saga ${ }^{2}$, and Words with Friends ${ }^{3}$. Games and puzzles were considered to be good for 'keeping the brain active' and an enjoyable social activity.

\section{Pocket Odyssey: Game Concept}

This section briefly describes the initial design of Pocket Odyssey. Design choices are based on identified requirements (see Table 1). Note that in time, as requirements change, decisions are necessarily going to change over the course of iterative development. However, the desired gaming experience remains intact.

Table 1. Identified design requirements

\begin{tabular}{|l|l|}
\hline R1 & Affect well-being in the emotional, psychological, social, and physical domain \\
\hline R2 & Engage players over time \\
\hline R3 & Adhere to usability needs for older audiences \\
\hline R4 & Provide a suitable game experience for the audience \\
\hline R5 & Utilise platform widely used by target audience (smartphone) \\
\hline R6 & Easily fit into existing routines \\
\hline R7 & Provide support during introduction \\
\hline R8 & Enable face-to-face contact \\
\hline R9 & Provide experience reminiscent of board games \\
\hline
\end{tabular}

In accordance with R5, the game suite has been designed to play solely on mobile phones, as this is a device that participants already own and is part of their routine (R6). In the game, a player takes on the role of an explorer uncovering mysteries as he/she travels through the world. This theme is based on themes distinguished in existing literature [7] and the exploratory survey (described above), in which the themes of travel, history, adventure, and mystery were reported, indicating alignment with user interests (R4). The game

\footnotetext{
1 Niantic, 2016

${ }^{2}$ King, 2016

${ }^{3}$ Zynga, 2009
} 
suite's main screen shows a player's personal ship. This provides the first distinct gameplay component, namely a customizable environment that requires periodic interaction with the player (R2). The other main component is that of expeditions: turn-based, online mystery-solving game sessions between 2 players (R1). As part of expeditions, players engage in mini-games, each of which tackles various aspects of well-being (R1). These games, in turn, can be used to host a local multi-player game session (R8), or be played on their own.

As stated above, a player's ship provides a customizable environment that develops over time. Its design is inspired by casual simulation games such as Animal Crossing ${ }^{4}$ and Farmville ${ }^{5}$. In these games, players perform short, repeating tasks to collect items and develop a virtual space (e.g. a house, town, or farm). This requires a player to leave the game temporarily and return at a later time. Therefore, regular interactions that can easily be slotted into 'idle' time are rewarded, addressing R2 and R7. Additionally, this particular type of game adheres to suggested aesthetics for older people (R4) [7]: 'nurturing', by building and customizing a personal space over time; 'curiosity', through unexpected items and effects; and 'nostalgia', through implementing recognizable objects from the past and the ability to add personal content. The option to add personal content (e.g. descriptions and photos), makes it possible to personalize a multi-player experience, even though interaction with the ship is mainly a single player activity. Players can view the decoration of the ships of others, and their personal content. This has been designed to make the game experience less impersonal and to promote social activity between players (R1).

Expeditions is a turn-based online game between 2 players, in which a virtual environment of a fictional society is explored. Players take turns in solving a mystery, based on questions about the fictional society. A randomized environment is revealed to players throughout the game as they uncover clues, on the basis of which a solution to the mystery can be devised. Players are encouraged to communicate with each other about clues they have found via a chat interface. The goal of this design is to integrate both collaborative and competitive elements and simulate a board game-like experience (R9).

Some clues in Expeditions require the completion of a randomized mini-game designed to stimulate light physical activity, cognitive training, or emotional training (R1). These mini-games may also be played individually or in a local multi-player session. Here, a random sequence of mini-games is assigned to individual players and projected on a larger shared screen. This last option changes the game experience to that of a shared, social, co-located group experience (R8) [2], with players competing to get the highest score. While mini-games have yet to be designed and implemented, each will be based on research and expert input related to the desired activity.

Pocket Odyssey will be further developed using an iterative user-centered design approach [9]. Initial paper prototypes have been tested with a small group of people with game design experience. The next phase includes involvement of

\footnotetext{
${ }^{4}$ Nintendo, 2001

${ }^{5}$ Zynga, 2009
} 
the target audience with a focus on usability (R3). Once the game has been 'finalized', training and support will be arranged (R7) for a one-year study in the three pilot countries involved in this project to examine user engagement and effects on well-being. The ultimate goal of this project is to identify game requirements and design guidelines for games designed to increase well-being over time through engagement.

\section{References}

1. Barlett, C.P., Anderson, C.A., Swing, E.L.: Video game effects - confirmed, suspected, and speculative: a review of the evidence. Simulation \& Gaming 40(3), 377-403 (2009)

2. Bianchi-Berthouze, N., Isbister, K.: Emotion and body-based games: Overview and opportunities. In: Emotion in Games, pp. 235-255. Springer (2016)

3. Brown, J.A.S.: Let's play: Understanding the role and significance of digital gaming in old age. University of Kentucky (2014)

4. Butler, J., Kern, M.L.: The perma-profiler: A brief multidimensional measure of flourishing. International Journal of Wellbeing 6(3) (2016)

5. Calleja, G.: In-game: From immersion to incorporation. MIT Press (2011)

6. Chamberlain, P., Craig, C.: Engagingdesign-methods for collective creativity. In: International Conference on Human-Computer Interaction. pp. 22-31. Springer (2013)

7. De Schutter, B.: Gerontoludic design: Extending the mda framework to facilitate meaningful play for older adults. International Journal of Gaming and ComputerMediated Simulations (IJGCMS) 9(1), 45-60 (2017)

8. Dodge, R., Daly, A.P., Huyton, J., Sanders, L.D.: The challenge of defining wellbeing. International journal of wellbeing $\mathbf{2}(3)$ (2012)

9. Fullerton, T.: Game design workshop: a playcentric approach to creating innovative games. CRC press (2014)

10. Gerling, K.M., Schulte, F.P., Smeddinck, J., Masuch, M.: Game design for older adults: effects of age-related changes on structural elements of digital games. In: International Conference on Entertainment Computing. pp. 235-242. Springer (2012)

11. Huppert, F.A., So, T.T.: Flourishing across europe: Application of a new conceptual framework for defining well-being. Social indicators research 110(3), 837-861 (2013)

12. Johnson, D., Jones, C., Scholes, L., Carras, M.C.: Videogames and wellbeing: A comprehensive review. Young and Well Cooperative Reseach Centre (2013)

13. Keyes, C.L.: Promoting and protecting mental health as flourishing: A complementary strategy for improving national mental health. American psychologist 62(2), $95(2007)$

14. Ryan, R.M., Rigby, C.S., Przybylski, A.: The motivational pull of video games: A self-determination theory approach. Motivation and emotion 30(4), 344-360 (2006)

15. Ryff, C.D.: Beyond ponce de leon and life satisfaction: New directions in quest of successful ageing. International journal of behavioral development 12(1), 35-55 (1989)

16. Seligman, M.E.: Flourish: A visionary new understanding of happiness and wellbeing. Simon and Schuster (2012)

17. Vella, K.: The social context of video game play: Relationships with the player experience and wellbeing. Ph.D. thesis, Queensland University of Technology (2016) 